\title{
Processamento e desgaste abrasivo de compósitos à base de epóxi-sílica para uso em coroas de polimento de rochas ornamentais
}

\author{
DE OLIVEIRA, O.C. ${ }^{\text {I}}$; MATOS, M.R. ${ }^{\text {I }}$; DE OLIVEIRA, L.J. ${ }^{\mathrm{I}}$; \\ BOBROVNITCHII, G.S. ${ }^{\text {I }}$; AIGUEIRA, R.B. ${ }^{\text {í }}$ FILGUEIRA, M. ${ }^{\mathrm{I}}$ \\ ${ }^{\text {I }}$ Universidade Estadual do Norte Fluminense - UENF/ Laboratório de Materiais Avançaos - LAMAV; \\ Av. Alberto Lamego, 2000, Campos dos Goytacazes/RJ, CEP: 28013-600. \\ e-mail: odivanco@yahoo.com.br, mariane@uenf.br, oliver@uenf.br, \\ rafaigueira@uenf.br, guerold@uenf.br, marcello@uenf.br
}

\section{RESUMO}

O presente trabalho desenvolve o processamento e ensaios abrasivos de compósitos a base do sistema epóxi-sílica $\left(\mathrm{SiO}_{2}\right.$ na forma quartzo), e avaliação da possibilidade de sua aplicação tecnológica nas coroas de polimento de rochas ornamentais, normalmente feitas a base do compósito cimento magnesiano (SOREL)-SiC. Neste sentido, foram produzidos compósitos nas estequiometrias epóxi - (70-75-80-85-90) \% em peso $\mathrm{SiO}_{2}$, via mistura e posterior cura, mediante emprego de catalisador. Os compósitos foram submetidos a testes de desgaste, simulando uma situação de polimento de rochas ornamentais. Confrontando os resultados obtidos para os compósitos produzidos com os do compósito cimento magnesiano (SOREL) $\mathrm{SiC}$ das coroas comerciais, observa-se a viabilidade técnica do uso deste novo compósito (epóxi-SiO ${ }_{2}$ ) na indústria de rochas ornamentais.

Palavras chaves: Compósito abrasivo, mecanismos de desgaste, polimento.

\section{Processing and abrasive wear of epoxy-silica based composites for use in polishing crowns of dimension stones}

\section{ABSTRACT}

This work deals with the processing and abrasive tests in epoxy - Silica composites, and the evaluation of the possibility of their technological application in dimension stones polishing crowns commonly made of magnesian mortar (named SOREL) - SiC.. In this sense the composites were processed at the compositions epoxy - (70-75-80-85-90) weight \% $\mathrm{SiO}_{2}$, by mixing and curing. The composites were submitted to wear tests, simulating a dimension stone polishing operation. Comparing the results obtained from the processed composites with those from the SOREL-SiC - commercial crowns, it was observed the technical feasibility of using the polyester-SiC composite in the dimension stone industry.

Keywords: Abrasive composite, wear mechanisms, polishing.

\section{INTRODUÇÃO}

O estudo em materiais para uso em ferramentas abrasivas nas atividades de beneficiamento de rochas ornamentais, tais como desbaste, polimento e lustre vêm crescendo bastante na última década [1], acompanhando a evolução experimentada na década de 80 até o momento pelas ferramentas de corte de rochas, do tipo disco serra, fios perolados, etc.

Coroas abrasivas são ferramentas empregadas para o beneficiamento de chapas de rochas ornamentais, que envolve o desbaste, polimento e lustre, etapas estas que se diferenciam basicamente pela granulometria dos abrasivos utilizados nas coroas. Estas ferramentas são feitas normalmente de partículas abrasivas de tamanhos variados, imersas em matrizes cerâmicas (argamassa de cimento), ou em matriz polimérica (poliéster ou epóxi). As partículas abrasivas são responsáveis pela ação de polimento e normalmente são de pó de diamante sintéticos (quando a matriz é polimérica), ou mais comumente de carbeto de silício (quando a matriz é SOREL). As matrizes, tanto cerâmica quanto polimérica, atuam como ligante, retendo as partículas abrasivas na ferramenta de polimento [ㄹ] . 
O desgaste da ferramenta inicia-se através do desgaste da partícula abrasiva, causando o seu abaulamento (planificação ou embotamento do grão abrasivo). Em seguida, a matriz polimérica também sofre um desgaste diminuindo a área na qual a partícula abrasiva se sustenta sobre tal matriz. Com o aumento deste desgaste até um ponto crítico, a partícula abrasiva se desprende e uma nova camada de partículas abrasivas começa a surgir. Esse desprendimento das partículas para o surgimento de uma nova camada é chamado de protusão ou "pull-out" [3] .

A explicação mais antiga do mecanismo de desgaste do diamante é que pequenos fragmentos da superfície resultante, provavelmente, são constituídos de uma série de asperezas cujas faces são planos de fácil clivagem [4]. Tem-se que a taxa de desgaste não aumenta com a temperatura, mas é dependente da direção de abrasão [5]. Entretanto, o mecanismo de desgaste mais aceito de uma ferramenta de corte à base de diamantes impregnados em matriz ligante foi fornecido por Wright e Wapler [్], e explanados por Davis et al [7]. Este mecanismo é ilustrado esquematicamente na figura 1, mostrando o comportamento da altura livre (altura de protusão - parte exposta, fora da matriz, responsável pelo corte) de uma partícula de diamante embebida na matriz, com o tempo, ou com a área de pedra cortada. Na região 1 ocorre o desgaste inicial da matriz e surgimento das faces cortantes das partículas abrasivas. A região 2 é denominada zona de trabalho constante, onde ocorre apenas um leve desgaste abrasivo da matriz ligante, e a região 3 é caracterizada pelo embotamento (início de planificação) do diamante e posterior quebra de sua ponta cortante, porém ocorre a auto-afiação da partícula abrasiva, mediante fricção contínua com a pedra. A região 4 é denotada pelo desgaste erosivo da matriz pela pedra, com liberação parcial das outras faces do diamante, até que, na região 5 ocorra a quebra da partícula, culminando com a protusão da mesma, na região 6 . Vale ainda ressaltar, que a figura abaixo não pode ser interpretada como um "gráfico protusão versus área cortada", porém, tem por objeto mostrar ou ilustrar o comportamento das partículas de diamantes embebidas na matriz metálica com o tempo de corte ou evolução do processo de desgaste.

\section{PROTUSÃO}

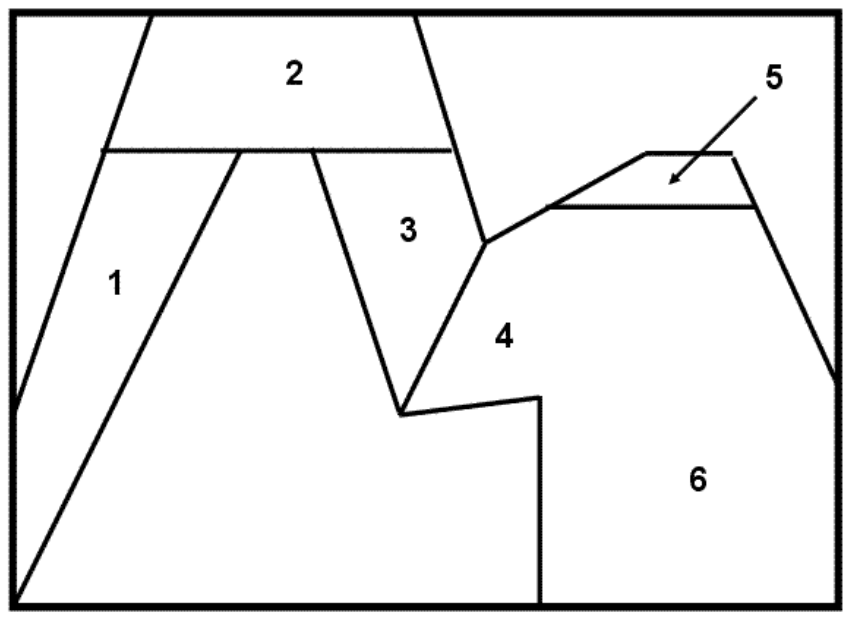

\section{ÁREA CORTADA OU TEMPO DE CORTE}

Figura 1: Tempo de vida hipotético de uma partícula de diamante, em termos de altura de protusão (extraído e modificado de [6] $]$ ).

O uso de abrasivos numa superfície sólida resulta em remoção de material. Do ponto de vista do material a ser trabalhado, o mecanismo de desgaste depende das propriedades mecânicas do sólido. Em um sólido dúctil, o mecanismo básico de desgaste está relacionado com a deformação plástica; paralelamente, a dureza é o parâmetro que governa a quantidade de material a ser removido. Entretanto, o mecanismo dominante de abrasão em material frágil depende predominantemente da fratura na superfície, de forma tal que a propriedade dominante é a tenacidade [ㅇ]

Visando o aumento na resistência à abrasão de uma ferramenta de desbaste, polimento e lustre à base de um compósito, adições de fases podem ser introduzidas no sistema, dentro de uma matriz dúctil ou frágil. Entretanto, as propriedades mecânicas requeridas pelo reforço e sua respectiva função, são bem diferentes para cada tipo de matriz (dúctil ou frágil). Para uma matriz dúctil, uma fase secundária dura é necessária para reduzir o desgaste de ferramenta. Por outro lado, um reforço tenaz é necessário para aumentar 
a resistência à abrasão em matriz frágil, pois a presença da fase tenaz reduz a tendência de fratura superficial do compósito $[\underline{8}, \underline{9}]$.

O presente trabalho visa o processamento e caracterização de um novo compósito para o polimento de rochas ornamentais, e posterior teste de desgaste, frente a coroas comerciais, e explanação qualitativa de seu mecanismo de desgaste. Estes compósitos são constituídos de pó de carbeto de sílica como partículas abrasivas duras, finamente dispersas numa matriz dúctil de epóxi, fato este que atende inteiramente aos comportamentos de desgaste ora mencionados. Com isto, espera-se trazer mais uma contribuição a um assunto ainda muito pouco explorado.

\section{PROCEDIMENTO EXPERIMENTAL}

Neste estudo são processados compósitos cuja matriz ligante é a resina poliéster, com partículas abrasivas $\mathrm{SiO}_{2}$ finamente dispersas, nos teores de 70-75-80-85-90 \% em peso. $\mathrm{O} \mathrm{SiO}_{2}$ utilizado tem tamanho médio de partícula de $560 \mu \mathrm{m}$, tamanho ideal para a primeira etapa de polimento de rochas ornamentais [2], pureza igual a $98 \%$, e densidade $2,65 \mathrm{~g} / \mathrm{cm}^{3}$. Esta sílica é oriunda de areia de praia do Farol de São Tomé (Campos dos Goytacazes/RJ), a qual foi lavada, secada e peneirada, e a fração aproveitada foi aquela retida entre as malhas \#20 e \#40 mesh.

O material utilizado como ligante, foi a resina epóxi líquida de especificação técnica Resina 8003, sendo esta uma resina a base de bisfenol A, fornecida pelo fabricante Epoxtec Produtos Químicos LTDA com densidade igual a $1,16 \mathrm{~g} / \mathrm{cm}^{3}$. Foi fornecido pelo mesmo fabricante da resina polimérica, o catalizador com especificação técnica de $21 \mathrm{Z}$ líquido, sem solventes à base de amina alifática. Para cada $100 \mathrm{~g}$ de poliéster, foram utilizadas 25 gramas de catalisador, segundo recomendação do fabricante. Foram preparadas 7 amostras de cada estequiometria, cujas dimensões médias são de $15 \mathrm{~mm}$ de altura X 12,7mm de diâmetro. Os lotes de 7 amostras por estequiometria foram destinados aos ensaios de desgaste, simulando a operação de polimento de rochas ornamentais. O material de ensaio foi um granito cinza, com estrutura orientada, de granulometria grossa - variando de 4 a $20 \mathrm{~mm}$, petrograficamente classificado como biotita monzogranito. Contém $32 \%$ de quartzo, $31 \%$ de microclina microperitítico, $24 \%$ de plagioclásio, $11 \%$ de biotita, e $2 \%$ de acessórios. Apresenta densidade de $2,67 \mathrm{~g} / \mathrm{cm}^{3}$, absorção d'água de $0,35 \%$, e porosidade total de $0,93 \%$. Foi produzido um disco deste granito com diâmetro externo e interno de, respectivamente, 80 e $48 \mathrm{~cm}$, e altura $5 \mathrm{~cm}$. Este disco foi instalado horizontalmente na mesa de um simulador físico tipo AMSLER modificadomicroprocessado modelo AB800-E fabricado pela CONTENCO. Cada amostra foi acoplada verticalmente ao disco de granito, em suporte com fixador e peso. Os parâmetros destes ensaios foram: carga vertical sobre as amostras de $5 \mathrm{kgf}$, rotação do disco de granito de 40 RPM, e tempo de ensaio de 2 minutos. Estes parâmetros foram calculados com base dos parâmetros utilizados nas politrizes industriais de rochas ornamentais, resguardando as dimensões das amostras em relação às das coroas comerciais. Durante os ensaios, o disco de granito gira na rotação desejada, e as amostras ficam paradas em um ponto, até o fim do ensaio. Antes e após os testes, a rugosidade do disco de granito é medida com um rugosímetro marca Mitutoyo de resolução $0,001 \mathrm{~mm}$. Estas medidas foram feitas em vários pontos, distantes $5 \mathrm{~mm}$ um do outro, ao longo de toda a trajetória perimetral de abrasão de cada amostra. Com base nestes resultados calculou-se o acabamento superficial do disco de granito, o desempenho de abrasão das amostras (DR), através da equação 1, e os cálculos de perda de massa $(\mathrm{PM})$ das amostras realizadas com o uso da equação 2, que corresponde à resistência à abrasão.

$$
D R=R A-R D
$$

onde: RA e RD são, respectivamente, a rugosidade do granito antes e após os ensaios de abrasão, em mm.

$$
P M=M I-M F
$$

onde: MI e MF são, respectivamente, as massas das amostras antes e após os ensaios de abrasão, em gramas.

Lotes de 5 amostras por estequiometria foram submetidos aos ensaios de compressão, haja visto que durante a operação de polimento, as coroas estão submetidas à carga média de 50kgf. Estes ensaios foram conduzidos em máquina de ensaios universal Instron 5582 , a uma velocidade de $2 \mathrm{~mm} / \mathrm{s}$.

Foi realizada a averiguação das microestruturas dos compósitos após os ensaios de abrasão, via microscopia eletrônica de varredura (MEV ZEISS DSM 962). Vale lembrar que lotes de amostras retiradas de coroa comercial à base de cimento magnesiano (SOREL) - $20 \%$ em peso $\mathrm{SiC}$ foram ensaiadas nas mesmas condições das amostras aqui produzidas, a efeito comparativo. 


\section{RESULTADOS E DISCUSSÃO}

\subsection{Ensaios de Polimento - Desgaste por Abrasão}

A tabela 1 fornece resultados de desempenho de abrasão (DR) e perda de massa (PM) dos compósitos processados, e do compósito SOREL-20\%peso SIC, retirado de coroas comerciais, calculados via uso das equações 1 e 2 . Nesta tabela, observamos que os compósitos do sistema epóxi contendo 80 e $85 \%$ p de $\mathrm{SiO}_{2}$ apresentaram os melhores resultados de capacidade de corte, uma vez que os mesmos contêm um maior volume de partículas abrasivas comparado aos compósitos contendo 70 e $75 \%$ p $\mathrm{SiO}_{2}$ e a amostra de sorel - $\mathrm{SiC}$. Contudo, a amostra com $90 \% \mathrm{p} \mathrm{SiO}_{2}$ não apresentou um resultado que superasse as demais amostras, pois o aumento do teor de partículas abrasivas na matriz dos compósitos (neste caso $\mathrm{SiO}_{2}$ ) promoveu melhora crescente no desempenho da ferramenta, mas até um certo limite, e a partir deste, o desempenho começou a cair, em conformidade com a literatura [3]. Neste trabalho, o sistema com $90 \%$ p $\mathrm{SiO}_{2}$ não apresentou uma área de contato suficientemente capaz de aderir as partículas abrasivas durante o ensaio de abrasão.

Tabela 1: Resultados obtidos: desempenho de abrasão (DR), perda de massa das amostras (PM) e perda de massa relativa (PM relativa - perda de massa do sorel-SiC dividido pela perda de massa da amostra).

\begin{tabular}{|c|c|c|c|}
\hline AMOSTRAS & $\mathrm{DR}(\mathrm{mm})$ & PM (g) & PM relativa \\
\hline Epóxi-70\%p $\mathrm{SiO}_{2}$ & 0,018 & $0,785 \pm 0,001$ & 1,103 \\
\hline Epóxi-75\%p $\mathrm{SiO}_{2}$ & 0,055 & $0,105 \pm 0,004$ & 8,281 \\
\hline Epóxi-80\%p $\mathrm{SiO}_{2}$ & 0,149 & $0,100 \pm 0,005$ & 8,663 \\
\hline Epóxi-85\%p $\mathrm{SiO}_{2}$ & 0,126 & $0,025 \pm 0,008$ & 34,642 \\
\hline Epóxi-90\%p $\mathrm{SiO}_{2}$ & 0,080 & $0,129 \pm 0,006$ & 6,713 \\
\hline Sorel-20\%p SiC & 0,032 & $0,866 \pm 0,008$ & 1 \\
\hline
\end{tabular}

O desempenho global é a avaliação entre o acabamento superficial (rugosidade) e a perda de massa por abrasão do compósito do produto, frente ao compósito da coroa comercial. Assim, a perda de massa relativa é igual a perda de massa do sorel-SiC dividido pela perda de massa do compósito produzido.

Via análise da tab.1, observa-se que os compósitos contendo 80 e $85 \%$ p de $\mathrm{SiO} 2$ apresentaram os melhores resultados de perda de massa relativa, 8,6 e 34,6 vezes superior ao sorel-SiC, respectivamente. Isto caracteriza que estes compósitos apresentaram uma área de contato (matriz-partícula) capaz de aderir as partículas abrasivas durante a operação de desbaste proporcionando um acabamento satisfatório, ou seja, um grau de rugosidade baixo e pouca produção de riscos na superfície do produto. Entretanto, para avaliar qual é comercialmente superior, deve ser feita uma análise da viabilidade econômica (custos), e tempo de vida útil dos compósitos, à nível industrial, o que não é alvo deste trabalho.

\subsection{Testes de compressão dos compósitos}

A figura 2 mostra os resultados obtidos do gráfico carga $(\mathrm{N})$ versus tempo (s), para as amostras contendo 70, 75, 80, 85 e 90\% de $\mathrm{SiO}_{2}$ em confronto com os resultados da amostra de sorel-SiC. Observa-se que dentre as amostras de epóxi- $\mathrm{SiO}_{2}$, a que obteve maior resistência foi a de $70 \%$ p $\mathrm{SiO}_{2}$, pois esta amostra apresenta uma maior quantidade de resina epóxi, oferecendo uma maior resistência a carga aplicada. Esta, por se tratar de um material polimérico apresenta valores de resistência a compressão significativamente elevados, pois durante sua cura praticamente não apresentou poros na estrutura.

Este ensaio teve por objetivo comparar a resistência à compressão dos compósitos processados frente ao comercial, uma vez que as coroas de desbaste e polimento de rochas ornamentais operam fixadas a uma máquina operatriz, sob carga média de $800 \mathrm{~N}$. 


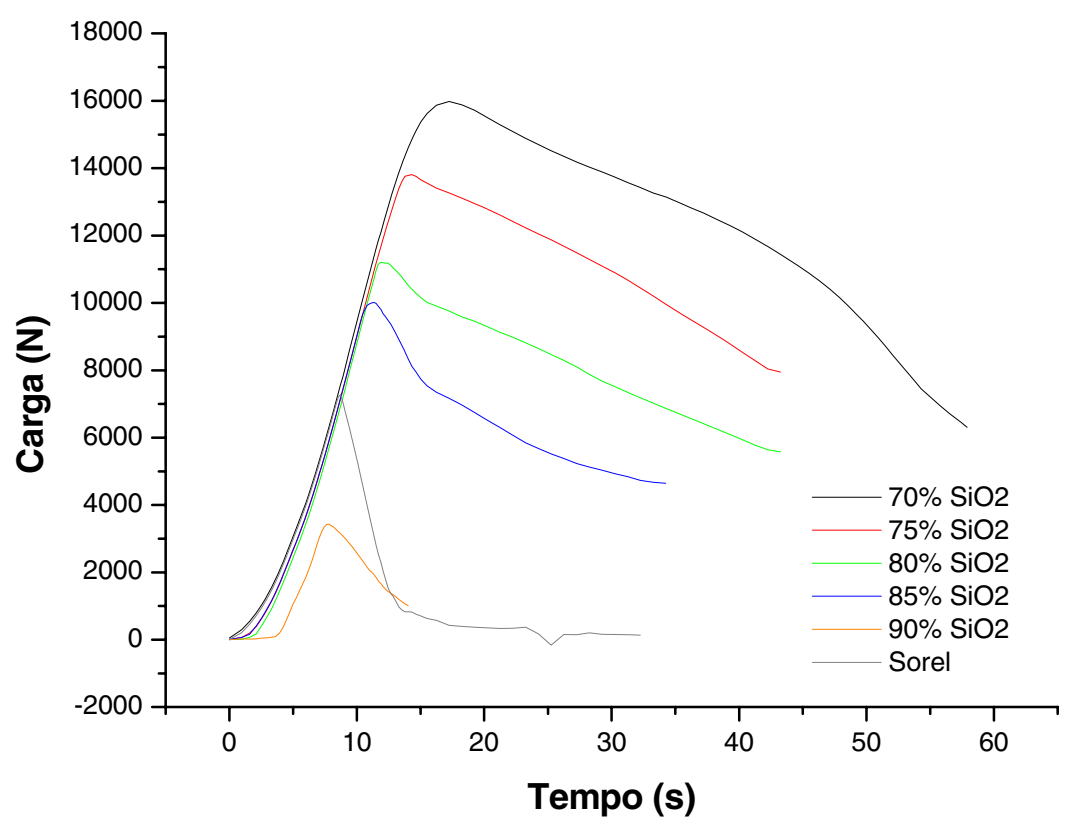

Figura 2: Gráfico carga versus tempo das amostras a base do sistema epóxi-SiO ${ }_{2}$ e sorel-SiC.

Apesar do sorel-20\%p SiC ser um material cerâmico, este apresentou valores de resistência a compressão superiores a amostra de $90 \% \mathrm{p} \mathrm{SiO}_{2}$, face ao elevado teor de partículas de sílica neste último, reduzindo a secção resistente de epóxi. Desta forma, apenas os compósitos epóxi- $90 \%$ p $\mathrm{SiO}_{2}$ não superam em resultados de resistência à compressão o compósito comercial de sorel-SiC.

\subsection{Superfícies de Desgaste dos Compósitos Abrasivos}

A figura 3.a mostra o aspecto microestrutural da superfície de desgaste da amostra de epóxi $-70 \%$ p $\mathrm{SiO}_{2}$, onde se observa que a matriz da resina epóxi sofreu elevado desgaste, decorrente do atrito com a superfície irregular do disco de granito. Na figura 3.b, que mostra o aspecto microestrutural de superfície de desgaste de amostra de epóxi-75\% $\mathrm{p} \mathrm{SiO}_{2}$, observa-se que a matriz apresenta-se com um desgaste menor, em comparação com a amostra epóxi-70\%p $\mathrm{SiO}_{2}$, e com um maior número de partículas de sílica ainda aderidas.

Analisando a figura 3.c, observa-se que a matriz polimérica não apresentou desgaste acentuado, como observado na figura 3.a, concluindo que a matriz proporcionou uma maior adesão das partículas abrasivas comparada ao compósito contendo $70 \% \mathrm{p}^{\mathrm{SiO}_{2}}$. Observa-se também, o desprendimento de partículas decorrente do processo de abrasivo, e o surgimento de novas partículas de $\mathrm{SiO}_{2}$ com superfície cortante que continuaram a promover a ação de desbaste.

Com base na figura 3.d (epóxi-85\%p $\mathrm{SiO}_{2}$ ), observa-se uma distribuição homogênea da matriz de epóxi com as partículas de $\mathrm{SiO}_{2}$, garantindo a retenção dos abrasivos durante o ensaio. Isto resultou ao compósito, uma menor perda de massa frente às demais amostras, tanto do sistema epóxi-SiO $\mathrm{Si}_{2}$ quanto do sorel-SiC, como observado na tab.1. Mesmo raciocínio se aplica na análise do seu desempenho global. 


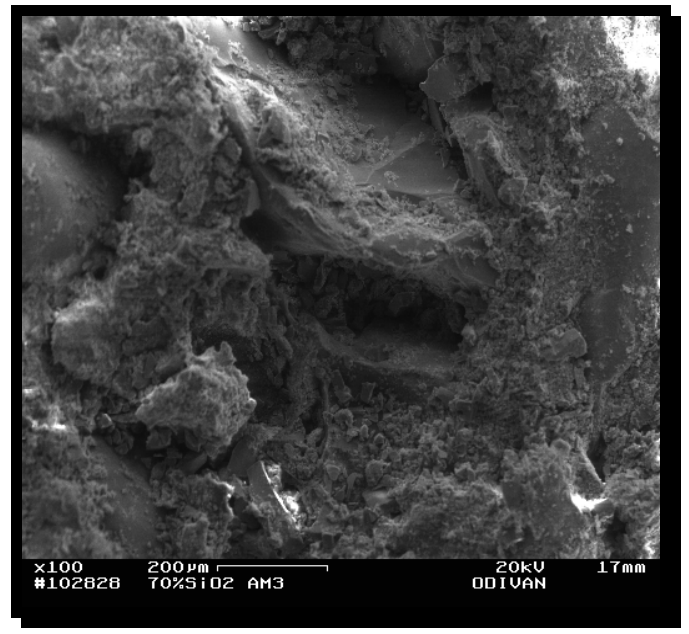

(a)

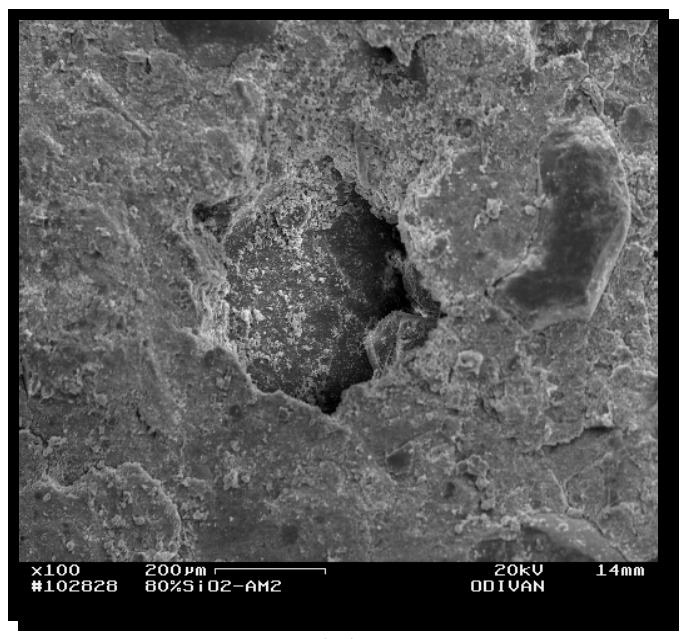

(c )

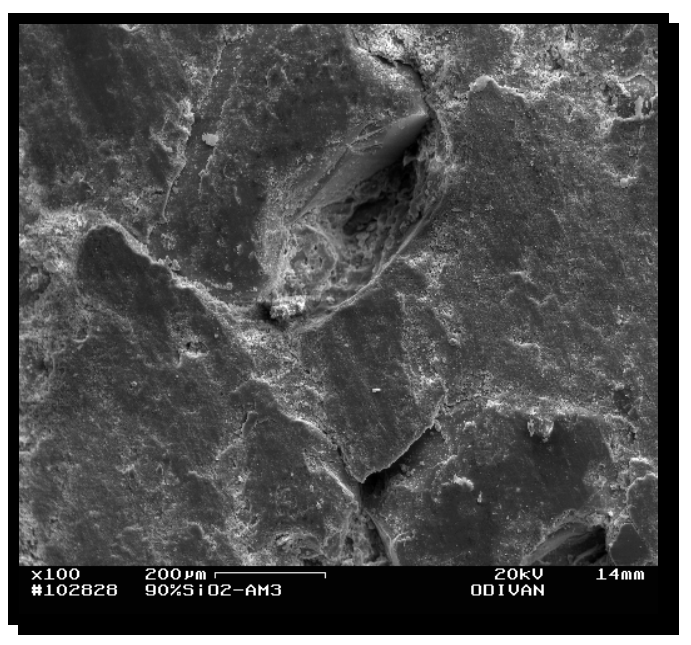

(e)

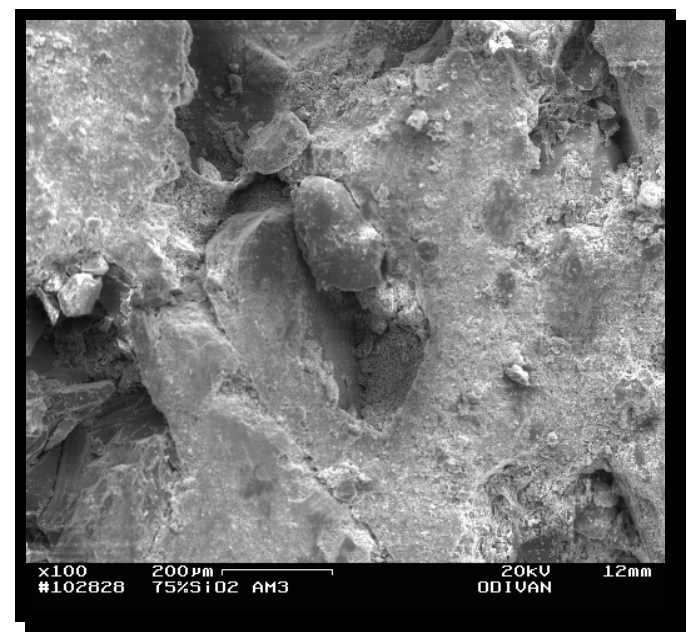

(b)

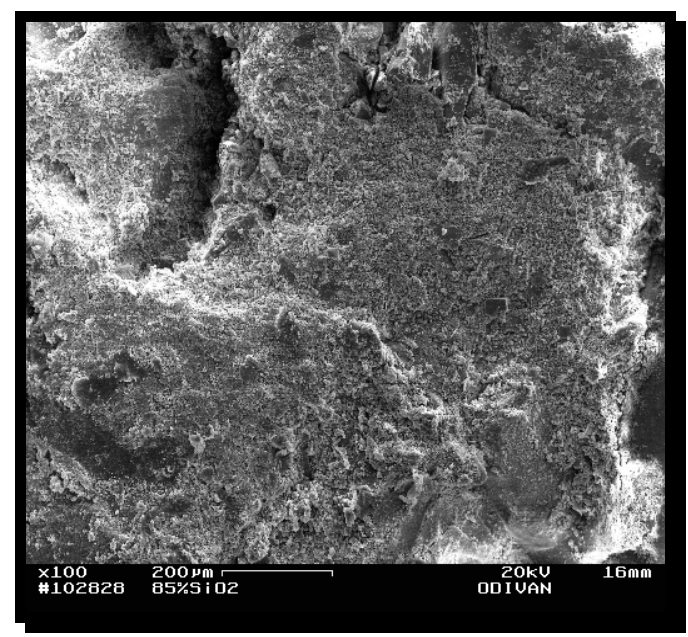

(d)

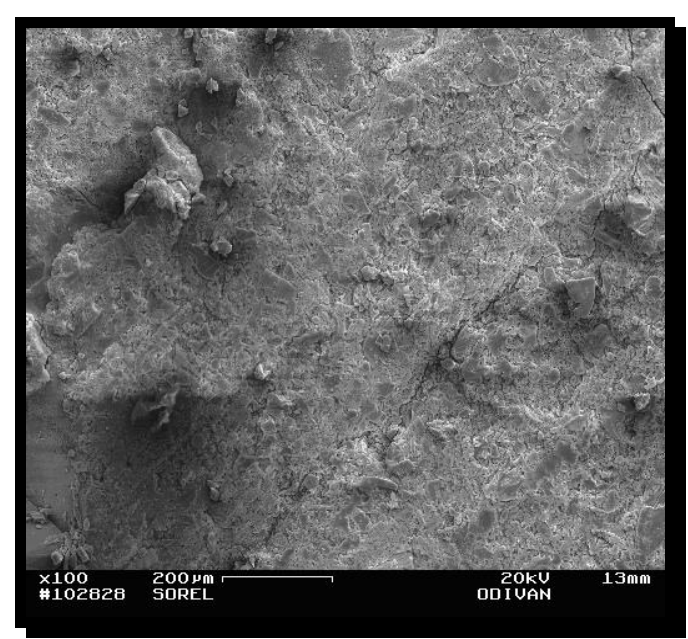

(f)

Figura 3: Superfícies de fratura das amostras: (a) epóxi-70\%p $\mathrm{SiO}_{2}$, (b) epóxi-75\%p $\mathrm{SiO}_{2}$, (c) epóxi-80\%p $\mathrm{SiO}_{2}$, (d) epóxi-85\% $\mathrm{p} \mathrm{SiO}_{2}$, (e) epóxi-90\% $\mathrm{SiO}_{2}$, (f) sorel-20\%p $\mathrm{SiC}$. 
$\mathrm{Na}$ observação da figura 3.e, revelam-se regiões planas referentes ao desgaste dúctil e regiões rugosas caracterizando o desgaste frágil. Estes desgastes ocorrem uma vez que a quantidade de partículas abrasivas é superior ao seu valor limite de abrasivos (conforme afirma a ref. [3] $)$. Frente a tal situação, o processo de desgaste da superfície torna-se competitivo, pois pode não ocorre o aplainamento, mas sim o deslizamento entre as superfícies compósito - granito levando a uma menor perda de massa do compósito $90 \% \mathrm{p} \mathrm{SiO}_{2}$ conforme analisado na tabela 9. Como conseqüência deste fato, o referido compósito apresentou um desempenho global inferior às demais amostras do sistema epóxi-SiO ${ }_{2}$.

A amostra de sorel-SiC apresentou uma superfície de desgaste pouco degradada como pode ser observado na figura 3.f. Esta micrografia revela também, que o poder de adesão da matriz não foi satisfatório, pois pode ser visto claramente poucas partículas abrasivas aderidas à matriz, o que é comprovado por ter apresentado a maior perda de massa em relação às demais amostras trabalhadas, como pode ser observado na tab.1. Além disso, a superfície de desgaste desta amostra revela que a sua degradação ocorre, por liberação de finas "escamas" da matriz, o que caracteriza o desgaste frágil, com a superfície da matriz permanecendo plana. Isto é de ser esperar, pois a matriz é de natureza cerâmica, não apresentando qualquer indício de dano térmico, apresentando, então, mecanismos de desgaste diferente da matriz polimérica.

\subsection{Comentários sobre o Mecanismo de Desgaste dos Compósitos Abrasivos}

Para estas duas classes de compósitos, epóxi- $\mathrm{SiO}_{2}$, matriz dúctil - abrasivo de alta dureza, e sorel$\mathrm{SiC}$, matriz frágil - abrasivo de alta dureza, para o uso em polimento de rochas ornamentais, o mecanismo de desgaste é definido como: 1) abrasão inicial da matriz ligante; 2) início do corte da pedra pelas partículas abrasivas; 3) embotamento das partículas até a planificação e posterior desprendimento da matriz - caso de uma satisfatória aderência matriz-partículas (matriz dúctil - partículas de alta dureza), vide figura 3.d. No caso de má aderência, as partículas, mesmo no início do polimento sofrem desprendimento, o que acarreta desgaste prematuro e excessivo da matriz (matriz frágil - partículas de alta dureza) - vide figura 3.f; 4) após o desprendimento, ocorreu um desgaste da matriz polimérica, e o surgimento de novas faces cortantes de outras partículas que estavam no "bulk", reiniciando o ciclo.

No mecanismo de desgaste acima descrito, o teor de partículas abrasivas no compósito apresenta enorme significado. Com o aumento deste teor, aumenta também o desempenho e vida útil da ferramenta, até um certo valor estequiométrico. Com o aumento do teor de partículas abrasivas, além do limite, a ferramenta sofre perda em suas propriedades, face à redução da área útil da matriz para a "ancoragem" das partículas abrasivas. Isto reduz drasticamente a aderência entre a matriz e as partículas, pois a tensão resistente da adesão é inversamente proporcional à área resistente de "ancoragem" - levando as partículas a se desprenderem prematuramente.

Do ponto de vista do mecanismo de desgaste dos compósitos, e à luz das micrografias da figura 3 , verifica-se que não há qualquer indício de processo de auto-afiação das partículas abrasivas, contrariamente ao mecanismo de desgaste observado nas refs. [6] e [7], porém em pleno acordo com Warnecke e Wimmer [10], ao avaliar o desgaste de coroa de matriz polimérica dúctil com diamante impregnado, durante o polimento de cerâmicas avançadas. Deve-se considerar também que o polimento de rochas ornamentais ocorre pela ação combinada da força vertical e da rotação impostas à ferramenta, que não ocorre nos processos de corte, o que torna o desgaste ainda mais drástico do que no caso descrito por Wright e Wapler [6] e por Davis et al [7], ou seja, devido ao giro relativo ferramenta-pedra, ocorre soltura prematura de partículas abrasivas.

\section{CONCLUSÕES}

Neste trabalho exploratório destacam-se as seguintes conclusões principais:

1) A rota desenvolvida para o processamento de compósitos à base do sistema epóxi- $\mathrm{SiO}_{2}$, para a aplicação como coroas abrasivas de desbaste e polimento de placas de rochas ornamentais, foi alcançada com sucesso sendo realizada com simplicidade e rapidez;

2) No mecanismo de desgaste dos compósitos estudados não ocorre auto-afiação das partículas abrasivas, sendo este desgaste dominado pelo comportamento dúctil da matriz epóxi, propiciando uma aderência satisfatória com o $\mathrm{SiO}_{2}$, o qual por sua vez sofreu aplainamento e soltura durante o polimento, mas propiciando o surgimento de novas partículas cortantes que se encontravam no " bulk" do compósito;

3) Dentre os compósitos a base do sistema epóxi- $\mathrm{SiO}_{2}$, comparando os resultados obtidos dos testes de desgaste juntamente com a análise das micrografias, as amostras que apresentaram melhor resultado foram as que possuem $85 \% \mathrm{p} \mathrm{SiO}_{2}$. Estas, além de superarem em 4 vezes a coroa abrasiva no desempenho de abrasão, mesmas apresentaram um resultado 34,6 vezes inferior ao da coroa comercial em termos de perda de massa, levando a um ganho muito grande no desempenho global. 


\section{REFERÊNCIAS}

[1] XU, X., "Experimental study on temperatures and energy partition at the diamond-granite interface", In: Grinding Tribology International, n. 34, pp. 419-426, 2001.

[2] AigueirA, R.B., BOBROVNITCHII, G.S., FILGUEIRA, M., "Processamento de um compósito abrasivo à base do sistema sic- $\beta$ - poliéster para polimento em rochas ornamentais", In: Anais do $59^{\circ}$ Congresso Anual da ABM, pp. 1527-1535, 2004.

[3] PRZYKLENK, K., "Diamond impregnated tools - uses and production", IDR - Toolmaking, v. 4. pp. 192-195, 1993.

[4] TOLKOWSKY, M., D. Sc. Thesis, University of London, 1920.

[5] WILKS, J., WILKS, E.M., “Abrasion and wear of diamond”, In: J.E. Field (ed.), Properties of Diamond, Academic Press, London, pp. $351-381,1979$.

[6] WRIGHT, D.N., WAPLER, H., "Investigations and prediction of diamond wear when sawing", In: Annals of the CIRP, v. 35, n. 1, pp. 239-244. 1986.

[7] DAVIS, P.R., et al, “An Indicator system for saw grit”, IDR, n. 3, pp. 78-87, 1996.

[8] LEE, G.Y., et al., "A physically-based abrasive wear model for composite materials", Wear, n. 252, pp. 322-331, 2002.

[9] LUO, S.Y., "Effect of fillers of resin-bonded composites on diamond retention and wear behavior", Wear, n. 236, pp. 339-349, 1999.

[10] WARNECKE, G., WIMMER, J., "Stock removal and wear in deep grinding high-performance ceramics", IDR, n. 3, pp. 126-132, 1995. 